\title{
Estrogen receptor- $\beta$ expression and pharmacological targeting in bladder cancer
}

\author{
ERIC C. KAUFFMAN ${ }^{1,2}$, BRIAN D. ROBINSON ${ }^{1,3}$, MARTIN DOWNES ${ }^{4}$, KATARZYNA MARCINKIEWICZ ${ }^{5}$, \\ SRINIVAS VOURGANTI ${ }^{6}$, DOUGLAS S. SCHERR ${ }^{1}$, LORRAINE J. GUDAS ${ }^{5}$ and NIGEL P. MONGAN ${ }^{3,4}$
}

\author{
${ }^{1}$ Department of Urology, Weill Cornell Medical College, New York, NY 10065; ${ }^{2}$ Departments of Urology and Cancer Genetics, \\ Roswell Park Cancer Institute, Buffalo, NY 14263; ${ }^{3}$ Department of Pathology and Laboratory Medicine, Weill Cornell \\ Medical College, New York, NY 10065, USA; ${ }^{4}$ Faculty of Medicine and Health Sciences, School of Veterinary \\ Medicine and Sciences, University of Nottingham, Sutton Bonington Campus, Leicestershire LE12 5RD, UK; \\ ${ }^{5}$ Department of Pharmacology, Weill Cornell Medical College, New York, NY 10065; ${ }^{6}$ Urologic Oncology Branch, \\ National Cancer Institute of the National Institutes of Health, Bethesda, MD 20892, USA
}

Received January 25, 2013; Accepted March 15, 2013

DOI: 10.3892/or.2013.2416

\begin{abstract}
A role for estrogen signaling in urothelial carcinoma of the bladder (UCB) is suggested to be associated with more advanced disease with worse outcomes in women. Estrogen receptor $\beta(E R \beta)$ is the predominant receptor in bladder tissues. We aimed to ascertain whether ER $\beta$ correlates with clinicopathological predictors of aggressive bladder cancer and worse survival outcomes. ER $\beta$ was measured by immunohistochemistry in malignant and adjacent benign bladder tissues in patients $(\mathrm{N}=72)$ with $\mathrm{UCB}$ who underwent radical cystectomy. ER $\beta$ expression was tested for statistical association with clinicopathological variables and patient survival. ER $\beta$ expression was determined in bladder cancer cell lines, and the effects of the selective estrogen modulator tamoxifen and the ER $\beta$ agonist diarylpropionitrile on cell growth were determined. The ER $\beta$ level was significantly higher in malignant vs. benign urothelium $(\mathrm{P}<0.001)$ and was strongly associated with aggressive tumor histology characterized by lymphovascular $(\mathrm{P}=0.008)$ and perineural $(\mathrm{P}=0.006)$ invasion, and clinical histories of pelvic irradiation $(\mathrm{P}=0.005)$, hydronephrosis $(\mathrm{P}=0.022)$ and no intravesical chemotherapy $(\mathrm{P}=0.038)$. All patients with a high $(>70 \%)$ percentage of ER $\beta$ positivity in tissue with $>3$-month follow-up developed recurrent disease $(\mathrm{P}=0.009)$. Higher $\mathrm{ER} \beta$ level was predic-
\end{abstract}

Correspondence to: Professor Lorraine J. Gudas, Department of Pharmacology, Weill Cornell Medical College, 1300 York Avenue, New York, NY 10065, USA

E-mail: ljgudas@med.cornell.edu

Dr Nigel P. Mongan, Faculty of Medicine and Health Sciences, School of Veterinary Medicine and Sciences, University of Nottingham, Sutton Bonington Campus, Leicestershire LE12 5RD, UK

E-mail: nigel.mongan@nottingham.ac.uk

Key words: epigenetic, hormonal, urothelial, transitional cell tive of worse recurrence-free and overall survival following cystectomy, after adjustment for tumor stage, and remained significantly associated with recurrence-free survival in the multivariable analysis including tumor stage, nodal stage and lymphovascular invasion. Activation of ER $\beta$ in bladder cancer cell lines led to significant increases in proliferation, while pharmacological inhibition with tamoxifen blocked cell growth. Our study supports a role for ER $\beta$ in aggressive UCB. Pharmacological targeting of ER $\beta$ warrants further investigation as a therapeutic strategy in UCB.

\section{Introduction}

Urothelial carcinoma of the bladder (UCB) is the fourth and tenth most common solid malignancy among US men and women, respectively (1). Radical cystectomy achieves a durable cure in most patients with organ-confined, lymph node-negative muscle-invasive or high-risk non-muscle invasive tumors, but a third of patients recur $(2,3)$. Worse oncologic outcomes are linked to surgical histopathology, including higher pT stage, lymphovascular invasion (LVI), lymph node metastasis and surgical margin involvement, as well as preoperative characteristics including female gender, hydronephrosis, pelvic radiation and lack of neoadjuvant chemotherapy (2-13). A role for hormonal factors in bladder carcinogenesis has been suggested by the male predominance $(\sim 3: 1)$ of UCB diagnoses in industrialized nations independent of tobacco usage or occupational carcinogen exposure (3). Estrogen plays a role in bladder development and homeostasis (14) and has been implicated in more advanced stage bladder tumors and worse bladder cancer-specific survival among females $(5-13,15)$. Epidemiologic support for a role of estrogen in bladder carcinogenesis includes a 50-60\% increase in UCB diagnoses among females with early menopause, bilateral oophorectomy or absence of combined estrogen-progesterone hormonal replacement therapy (16-18). A 2-fold increase in UCB incidence is also observed among nulliparous women, possibly related to unopposed estrogen (16). 
The estrogen receptor genes, ER $\alpha$ and ER $\beta$, have differential tissue expression patterns and functions (19). An important role for estrogen signaling is becoming apparent in UCB (20-24). ER $\beta$ protein is the predominant ER in bladder, expressed in up to $77 \%$ of clinical UCB, whereas ER $\alpha$ expression is infrequent $(<5 \%)(22,25,26)$. ER $\beta$ expression is unrelated to UCB patient gender or age, but has not been studied with regard to other clinical risk factors, such as smoking or radiation. Furthermore, the relationship between ER $\beta$ and tumor stage or patient outcomes is disputed $(22,25,26)$, and the relationship of ER $\beta$ to histological cancer features such as perineural invasion, concomitant carcinoma in situ or LVI has not yet been described. While selective estrogen receptor modulators (SERM) have been shown to inhibit the proliferation of some UCB cell lines and murine xenografts, which ER isoform(s) is being targeted has not been addressed (20-24). Research in preclinical models has generally not interrogated the ER $\beta$ isoform specifically, with most studies evaluating a non-specific ER $\alpha / E R \beta$ agonist in UCB cell lines expressing both ER $\alpha$ and ER $\beta$.

As ER $\beta$ is the predominant estrogen receptor isoform in normal and malignant bladder tissue, our study aimed to better delineate the role of ER $\beta$ in bladder carcinogenesis. We quantified ER $\beta$ expression in both malignant and benign tissues from UCB patients undergoing cystectomy and tested its association with tumor pathology, including for the first time histological features such as lymphovascular, perineural invasion and concomitant carcinoma in situ, in addition to survival outcomes. We also provide the first investigation of ER $\beta$ in relation to known clinical risk factors for UCB diagnosis and UCB-specific mortality including smoking history, race, pelvic radiation, hydronephrosis and neoadjuvant chemotherapy. Finally, we evaluated the effect of selective ER $\beta$ activation on UCB cell line proliferation with and without SERM treatment. Our findings indicate a crucial role for ER $\beta$ in UCB, including a novel stage-independent association with aggressive cancer histology and poor survival outcomes after cystectomy, and suggest clinical utility of ER $\beta$ pharmacologic targeting in this disease.

\section{Materials and methods}

Patients and tissue specimens. Institutional Review Board approval was acquired for this study. Tissue samples $(\mathrm{N}=129)$, including urothelial cell carcinomas $(\mathrm{n}=59)$ and benign urothelium ( $\mathrm{n}=70$ ), were obtained from May 2002 to December 2007 at the Department of Pathology and Laboratory Medicine, New York Presbyterian Hospital, Weill Cornell Medical College as previously described (27). All patients had preoperatively diagnosed UCB and underwent pelvic lymphadenectomy during cystectomy. Thirteen patients with no detectable cancer (pT0) at surgery had only benign urothelium acquired. All but two patients without pT0 disease had both benign and malignant tissue samples obtained; the two remaining patients had large primary tumors such that only malignant tissue was available. Death certificates and autopsy reports were reviewed to determine cause of death as cancer-related or from other causes.

Immunohistochemistry. Immunohistochemical staining for human ER $\beta$ protein (14C8 antibody, 1:300 dilution; Novus
Biologicals, Littleton, CO, USA) was performed using the Leica BOND-MAX Autostainer and the Leica Microsystems Refine Detection kit as previously described (27). Negative controls were performed without the primary antibody and with normal mouse serum. Benign and malignant prostate tissues were used as a positive control. All stained tissue sections were evaluated by a urologic pathologist (B.D.R.), and separate scores were assigned to each sample based on: i) the percentage of tissue staining positive (0-100\%); and ii) intensity of positively staining cells (none, 0 ; weak, 1 ; moderate, 2; and strong, 3) as previously described (27). Only nuclear staining was considered positive, and a minimum of 100 tumor nuclei was evaluated per case.

Bladder cancer cell lines, culture conditions, RNA extraction and $q R T-P C R$. The HTB-1 (J82), HTB-5 (TCCSUP) and HT1376 UCB cell lines were derived from high-grade invasive urothelial carcinomas, and the HTB-3 (SCaBER) cell line was derived from an invasive squamous cell carcinoma of the bladder (ATCC, Rockville, MD, USA). RNA was extracted and cDNA was synthesized as previously described (27). Primers for ER $\alpha$ and ER $\beta$ were as previously described (22) and HPRT (5'-tgctcgagatgtgatgaagg-3' and 5'-tccectgttgactggtcatt-3') was used as a normalizing control. cDNA from the MCF-7 breast cancer cell line was used as a positive control, and expression of ER $\alpha$ and ER $\beta$ was normalized by $H P R T$ and compared to the levels detected in MCF-7 using the $\triangle \Delta \mathrm{Ct}$ qPCR method.

Effects of ER agonists and a selective ER modulator on bladder cancer cell growth. The effects of $17 \beta$-estradiol (E2) (Sigma-Aldrich, St. Louis, MO, USA) and selective ER $\beta$ agonist diarylpropionitrile (DPN) (Tocris, Minneapolis, MN, USA), with and without tamoxifen (Sigma Aldrich), were assessed on bladder cancer cell lines at a $10 \mathrm{nM}$ concentration as previously reported $(22,28)$. Cells $\left(1 \times 10^{6} /\right.$ well $)$ were treated with the drugs for $48 \mathrm{~h}$ and the number of cells was counted using a Coulter Counter (Beckman-Coulter, Brea, CA, USA). Each treatment condition represents a minimum of 12 data points accrued over 4 separate experiments.

Statistical analysis. Fisher's exact test was used to test for statistical association between ER $\beta$ immunostaining scores and clinicopathological variables (Table I). The staining percentage was assessed as a categorical variable using a 4-tier scale $(0-10 \%, 11-40 \%, 41-70 \%$ and $71-100 \%)$, while staining intensity was assessed using a 0-3 scale, as previously described (27). Patients with a final pathology of primary $\mathrm{UCB}$ in situ (pTis) were censored from the analysis testing for association with concomitant CIS. The Kaplan-Meier method was used to analyze disease-free, cancer-specific and overall survival curves stratified by ER $\beta$ immunostaining scores. Time to recurrence or death was compared between groups using a log-rank test. A multivariable Cox proportional hazards model tested the ability of immunostaining scores to predict survival outcomes after adjusting for pathologic tumor stage. A second Cox proportional hazards model was also constructed which included ER $\beta$ staining, pathologic tumor stage, LVI and lymph node stage. For in vitro growth assays, two-tailed t-tests were utilized to compare the effects on cellular proliferation of individual drug treatments relative to solvent control and between 
Table I. Characteristics of the cystectomy patients.

\begin{tabular}{|c|c|}
\hline \multicolumn{2}{|l|}{ Characteristics } \\
\hline Total patients, n (\%) & $72(100)$ \\
\hline \multicolumn{2}{|l|}{ Age (years) } \\
\hline Mean \pm SD & $66.4 \pm 10.0$ \\
\hline Median & 66.6 \\
\hline Range & 43.3-88.8 \\
\hline \multicolumn{2}{|l|}{ Gender, n (\%) } \\
\hline Female & $21(29)$ \\
\hline Male & $51(71)$ \\
\hline \multicolumn{2}{|l|}{ Race, n (\%) } \\
\hline Caucasian & $66(92)$ \\
\hline Other & $6(8)$ \\
\hline \multicolumn{2}{|l|}{$\mathrm{BMI}, \mathrm{kg} / \mathrm{m}^{2}$} \\
\hline Mean \pm SD & $26.8 \pm 4.8$ \\
\hline Median & 26.5 \\
\hline Smoking history, n (\%) & $56(74)$ \\
\hline Active smoker, n (\%) & $15(21)$ \\
\hline Prior pelvic irradiation, n (\%) & $8(11)$ \\
\hline Prior intravesical chemotherapy, n (\%) & $21(29)$ \\
\hline Prior neoadjuvant systemic chemotherapy, n (\%) & $11(15)$ \\
\hline Pre-operative hydronephrosis, n (\%) & $20(28)$ \\
\hline \multicolumn{2}{|l|}{ Pathological stage, n (\%) } \\
\hline pT0 & $13(18)$ \\
\hline $\mathrm{pTa}$ & $9(13)$ \\
\hline pTis & $11(15)$ \\
\hline pT1 & $7(10)$ \\
\hline pT2 & $10(15)$ \\
\hline pT3 & $11(15)$ \\
\hline pT4 & $11(15)$ \\
\hline Lymph node metastases, n (\%) & $18(25)$ \\
\hline \multicolumn{2}{|l|}{ N-stage } \\
\hline $\mathrm{N} 1$ & $10(14)$ \\
\hline $\mathrm{N} 2$ & $5 \quad(7)$ \\
\hline N3 & 3 (4) \\
\hline Lymphovascular invasion (LVI), n (\%) & $15(21)$ \\
\hline Perineural invasion, $\mathrm{n}(\%)$ & $6(8)$ \\
\hline Concomitant carcinoma in situ (CIS), n (\%) & $34(47)$ \\
\hline
\end{tabular}

drug combinations. Statistical analyses were conducted using IBM SPSS Statistics (version 19.0.1.80), Prism (GraphPad Software Inc., La Jolla, CA, USA) or JMP version 8 (SAS Institute Inc., Cary, NC, USA). In all cases, $\mathrm{P} \leq 0.05$ was considered to indicate a statistically significant result.

\section{Results}

Association of ER $\beta$ immunostaining with bladder cancer histopathology and clinical risk factors. The majority of cases

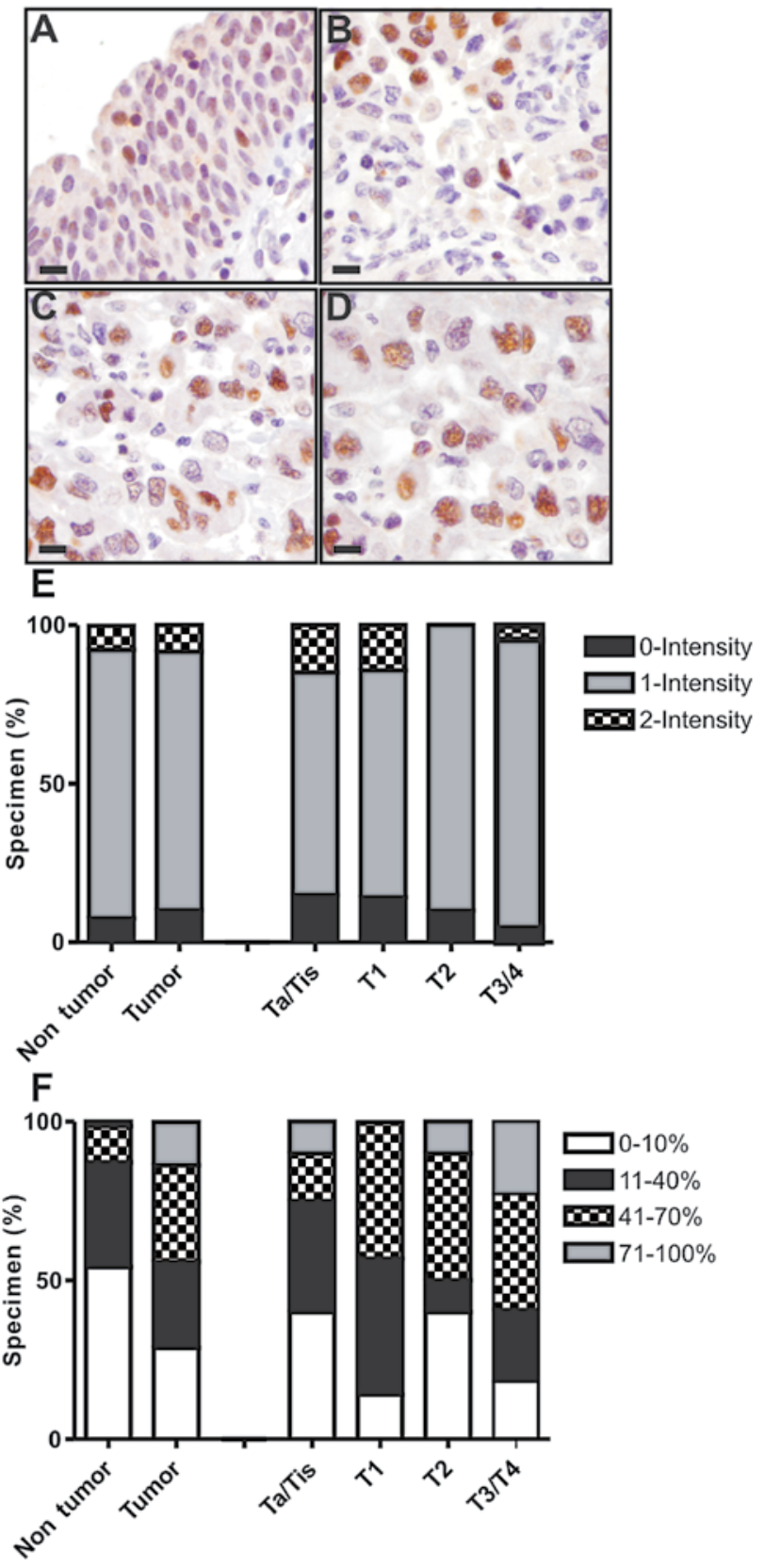

Figure 1. Immunohistochemical staining. Representative immunohistochemical staining for ER $\beta$ in (A) benign urothelium, (B) non-muscle invasive urothelial carcinoma (pTis, pTa, pT1), (C) muscle invasive carcinoma (pT2) and (D) extravesical (pT3) carcinoma. (All images were captured at x400 total magnification; bar, $20 \mu \mathrm{m}$ ). (E and F) Distribution of staining positivity and intensity according to pathological stage. Separate scores were assigned to the stained tissue sections based on $(\mathrm{E})$ the intensity of positively staining cells ( 0 , none; 1 , weak; 2 , moderate; and 3 , strong) and on (F) tissue positivity, i.e., the percentage of tissue staining positive $(0-100 \%)$. Only nuclear staining was considered positive, and a minimum of 100 tumor nuclei were counted for each case. Please refer to Table II for detailed statistical analysis.

had only low (1+) intensity ER $\beta$ staining (Fig. 1). Staining positivity (percentage of tissue) was significantly elevated in cancer tissues compared to benign bladder tissues $(\mathrm{P}<0.001)$ (Fig. 1, Table II). For example, $\sim 80 \%$ of cancer specimens had $>10 \%$ tissue positivity, compared to a minority of benign specimens (Fig. 1). High tissue positivity ( $>70 \%$ ) was observed exclusively in cancer specimens (Fig. 1). ER $\beta$ staining was not associated with tumor stage (Fig. 1), including different 
Table II. Association of ER $\beta$ with patient histopathological traits, disease recurrence and cancer-specific mortality in tumor specimens.

\begin{tabular}{|c|c|c|c|c|}
\hline \multirow[b]{2}{*}{ Histopathological parameters } & \multicolumn{2}{|c|}{ Tumor $(\mathrm{n}=59)$} & \multicolumn{2}{|c|}{ Benign urothelium $(n=70)$} \\
\hline & ER $\beta$ positivity $\%$ & ER $\beta$ intensity & ER $\beta$ positivity $\%$ & $\mathrm{ER} \beta$ intensity \\
\hline Stage (overall) & 0.448 & 0.326 & 0.499 & 0.694 \\
\hline Non-muscle invasive vs. invasive & 0.197 & 0.290 & 0.540 & 0.288 \\
\hline NMI vs. MI & 0.218 & 0.149 & 0.425 & 0.493 \\
\hline BC vs. EVE & 0.249 & 0.457 & 0.105 & 0.043 \\
\hline Lymphovascular invasion & 0.008 & 0.389 & $\mathbf{0 . 0 3 3}$ & 0.317 \\
\hline Perineural invasion & 0.006 & 1 & 0.493 & 1 \\
\hline Comcomitant carcinoma in situ & 0.230 & 0.323 & 0.628 & 0.823 \\
\hline Positive bladder margin & 0.769 & 1 & 0.841 & 1 \\
\hline
\end{tabular}

Fisher's exact P-values are shown for each statistical association. Bold print indicates significance $(\mathrm{P}<0.05)$. Non-muscle invasive $($ Ta, $\mathrm{T} 1$ and CIS) and muscle invasive (T2, T3 and T4) bladder cancers. NMI, non-muscle invasive; MI, muscle invasive; BC, bladder confined; EVE, extravesical.

Table III. Association of ER $\beta$ with patient clinicopathological traits, disease recurrence and cancer-specific mortality in tumor specimens.

\begin{tabular}{|c|c|c|c|c|}
\hline \multirow[b]{2}{*}{ Clinical parameters } & \multicolumn{2}{|c|}{ Tumor $(n=59)$} & \multicolumn{2}{|c|}{ Non-tumor $(n=70)$} \\
\hline & ER $\beta \%$ positivity & ER $\beta$ intensity & ER $\beta \%$ positivity & $\mathrm{ER} \beta$ intensity \\
\hline Age (years) & 0.283 & 0.630 & 0.156 & 0.373 \\
\hline Gender & 0.791 & 1 & 0.952 & 0.199 \\
\hline Race & 0.183 & 0.801 & 0.018 & 0.398 \\
\hline \multicolumn{5}{|l|}{ Smoking } \\
\hline Any history & 0.399 & 0.819 & 0.813 & 1 \\
\hline Active & 0.478 & 1 & 0.441 & 1 \\
\hline Body mass index & 0.198 & 0.928 & 0.139 & 0.677 \\
\hline Prior pelvic radiation & 0.005 & 0.310 & 0.418 & 0.771 \\
\hline Hydronephrosis & 0.022 & 0.122 & 0.393 & 1 \\
\hline Intravesical chemotherapy & 0.038 & 0.194 & 0.083 & 0.330 \\
\hline Neoadjuvant chemotherapy & 0.292 & 0.462 & 0.701 & 0.385 \\
\hline
\end{tabular}

Fisher's exact $\mathrm{P}$-values are shown for each statistical association. Bold print indicates significance $(\mathrm{P}<0.05)$.

substage comparisons (Table II). However, ER $\beta$ positivity in cancer specimens was strongly associated with aggressive bladder cancer histological features, namely LVI and perineural invasion $(\mathrm{P}<0.01$ each; Table II). All cancers with LVI had at least low ( $>10 \%)$ ER $\beta$ positivity, and all cancers with perineural invasion had at least moderate ( $>40 \%)$ ER $\beta$ positivity. The presence of LVI was also associated with ER $\beta$ positivity in the adjacent benign urothelium (Table II).

ER $\beta$ levels were also tested for association with clinical variables, including risk factors for UCB diagnosis or UCB-specific mortality (Table III). ER $\beta$ positivity in cancer specimens was associated with prior pelvic radiation and hydronephrosis (Table III), with $>70 \%$ positivity found in $\sim 50$ and $\sim 33 \%$ of cancer specimens with these traits, respectively. ER $\beta$ positivity was inversely associated with a history of intravesical chemo- therapy, with minimal or low staining in the vast majority (82\%) of cancer specimens from these patients. ER $\beta$ positivity was associated with race in benign specimens.

Association of ER $\beta$ immunostaining with bladder cancer patient survival outcomes. Median and mean patient follow-up after radical cystectomy was 21 and 26 months, respectively. Recurrence occurred in 21/72 (29\%) patients, 15/72 (21\%) died from their disease, and an additional 10/72 (14\%) patients died of other causes. All patients with a high $(>70 \%)$ percentage of ER $\beta$ positivity in tissue at $>3$-month follow-up developed recurrent disease. Tumor stage, lymph node stage $(\mathrm{P}=-0.0001)$, LVI $(\mathrm{P}=0.03)$ and elevated $\mathrm{ER} \beta$ positivity $(\mathrm{P}=0.009)$ were significantly inversely associated with recurrence-free, cancer-specific and overall survival in the Cox univariable 

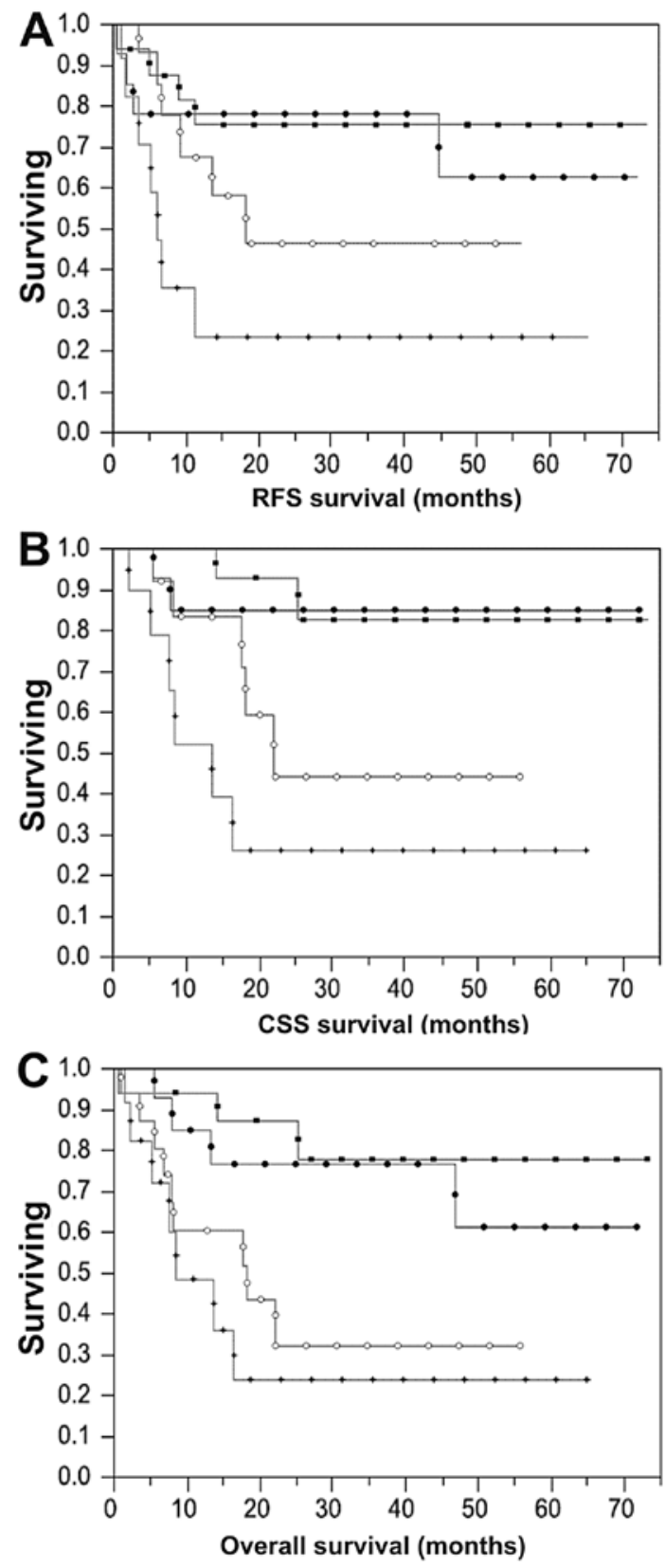

Figure 2. Kaplan-Meier survival estimates. Kaplan-Meier estimates stratified by percentage of ER $\beta$ positivity in tissue (square, $0-10 \%$; open circle, 11-40\%; black circle, $41-70 \%$; star, $71-100 \%$ ) for (A) recurrence-free survival (RFS) $(\mathrm{P}=0.030),(\mathrm{B})$ cancer-specific survival $(\mathrm{CSS})(\mathrm{P}=0.0018)$, and $(\mathrm{C})$ overall survival $(\mathrm{P}=0.0061)$.

analysis (Table IV). Each of these variables also correlated with shorter time to recurrence, cancer-specific or all-cause mortality on log-rank tests, as depicted for ER $\beta$ in Fig. 2. No association between ER $\beta$ intensity in cancer specimens and time to recurrence, cancer-specific or all-cause mortality was observed $(\mathrm{P}=0.59,0.32,0.54$, respectively). There was also no association between ER $\beta$ intensity or positivity in adjacent benign urothelium and time to recurrence, cancer-specific or all-cause mortality $(\mathrm{P}=0.62,0.08,0.28$ and $0.28,0.07,0.18$, respectively).

In Cox multivariable analysis including ER $\beta$ positivity and tumor stage, both variables remained significantly inversely associated with recurrence-free and overall survival; tumor stage $(\mathrm{P}=0.02)$ but not $\mathrm{ER} \beta(\mathrm{P}=0.07)$ remained significantly associated with cancer-specific survival, likely because of the limited number of cancer-specific death events. A second multivariable analysis of survival outcomes was performed with ER $\beta$ positivity, tumor stage, lymph node stage and LVI. In this second analysis, increased ER $\beta$ positivity still remained significantly inversely associated with recurrence-free survival $(\mathrm{P}=0.02)$ independent of these variables (Table IV).

Effects of ER $\beta$ activation and selective ER modulation on bladder cancer cell growth. $\mathrm{ER} \alpha$ and $\mathrm{ER} \beta$ mRNA expression was evaluated in the HTB-1 (J82), HTB-3 (SCaBER), HTB-5 (TCC-SUP) and HT1376 (CRL-1472) bladder cancer cell lines. All four cell lines expressed transcripts for ER $\beta$ but not ER $\alpha$ as compared to the MCF-7 breast cancer cell line (Fig. 3A and B). Treatment with estradiol resulted in a significant increase in HTB-1, HTB-3 and HTB-5 proliferation, whereas the selective ER modulator and ER $\beta$ antagonist tamoxifen inhibited proliferation of HTB-1 and HT1376 cells, the two cell lines with the highest ER $\beta$ expression (Fig. 3B). The ER $\beta$-selective agonist DPN induced a significant increase in proliferation in all three UCB cell lines tested (Fig. 3C, E and F) relative to the control treated cells. DPN did not affect proliferation of the squamous HTB-3 cell line (Fig. 3D), which exhibited the lowest ER $\beta$ expression (Fig. 3B). DPN-induced cellular proliferation was inhibited by tamoxifen in all cell lines (Fig. 3). These results indicate that hormonal activation of ER $\beta$ promotes UCB cell proliferation and that this can be blocked by tamoxifen.

\section{Discussion}

Identification of the molecular mechanisms governing bladder carcinogenesis is critical for the development of novel pharmacotherapies and biomarkers for this disease. Despite clinical observations of more advanced UCB and shorter survival among female patients, in addition to an established role for ER $\beta$ in bladder development and function (14), controversy remains over the contributions of estrogen signaling to bladder carcinogenesis $(5-13,15-18)$. ER $\beta$ has been implicated in endocrine-related human malignancies, notably invasive prostate cancers (19). Previous studies of $\mathrm{ER} \alpha$ and ER $\beta$ expression in UCB specimens yielded inconsistent results $(22,25,26,29,30)$ and have been limited to a subset of available UCB preclinical models $(22,28,29)$.

We sought to clarify these findings by examining ER $\beta$ in a well-described UCB patient cohort (27) and additional bladder cancer cell lines. Among the UCB patients, we found no association between ER $\beta$ and tumor stage, but uncovered a novel association between elevated $\operatorname{ER} \beta$ and aggressive bladder histology characterized by perineural invasion and LVI, the latter being a well-established independent predictor of worse oncologic outcomes. In addition, our findings demonstrated that elevated ER $\beta$ predicts reduced survival among cystectomy patients with all UCB stages, and provide the first demonstration that this association is independent of tumor stage. ER $\beta$ expression remained significantly associated with recurrence-free survival after adjusting for other established independent predictors of cystectomy patient outcomes, including lymph node stage and LVI. We thus identified ER $\beta$ as an independent biomarker for poor cystectomy patient 
Table IV. Multivariable associations of survival outcomes.

\begin{tabular}{|c|c|c|}
\hline Univariate analysis & Multivariable analysis 1 & $\underline{\text { Multivariable ana }}$ \\
\hline (P-value) & $\begin{array}{l}\text { pT stage } \\
\text { (P-value) }\end{array}$ & $\begin{array}{r}\text { pT stage, } \\
\mathrm{N} \text { stage and } \mathrm{L} \\
(\mathrm{P} \text {-value })\end{array}$ \\
\hline 0.0090 & 0.029 & 0.017 \\
\hline$<0.0001$ & $<0.0001$ & 0.0004 \\
\hline 0.0001 & - & 0.14 \\
\hline 0.030 & - & 0.91 \\
\hline 0.0014 & 0.11 & 0.26 \\
\hline$<0.0001$ & 0.016 & 0.071 \\
\hline 0.0012 & - & 0.83 \\
\hline 0.0017 & - & 0.89 \\
\hline 0.0061 & 0.041 & 0.067 \\
\hline$<0.0001$ & $<0.0001$ & 0.017 \\
\hline 0.0003 & - & 0.58 \\
\hline$<0.0001$ & - & 0.035 \\
\hline
\end{tabular}

Recurrence-free survival

Percentage of ER $\beta$ positivity in tissue

0.0004

PT stage

Lymphovascular invasion

Cancer-specific survival

Percentage of ER $\beta$ positivity in tissue

pT stage

$\mathrm{N}$ stage

Lymphovascular invasion

Overall survival

Percentage of ER $\beta$ positivity in tissue

pT stage

$<0.0001$

Multivariable analysis 1 includes ER $\beta$ percentage and pT stage. Multivariable analysis 2 includes ER $\beta$ percentage, pT stage, N stage and lymphovascular invasion (LVI).

A

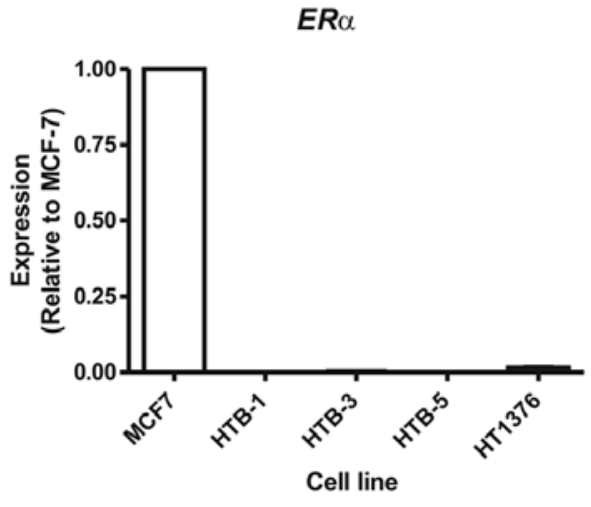

B



C
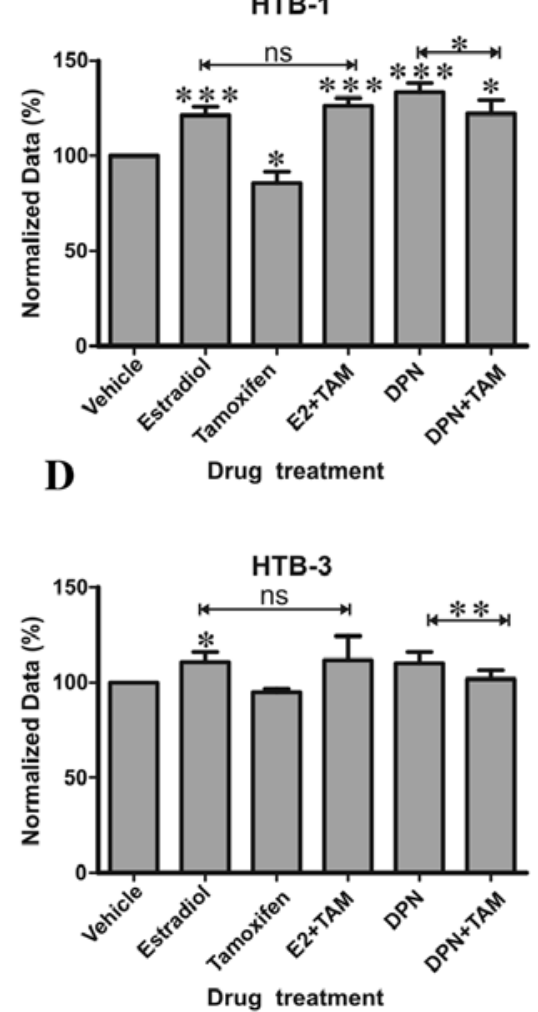

E
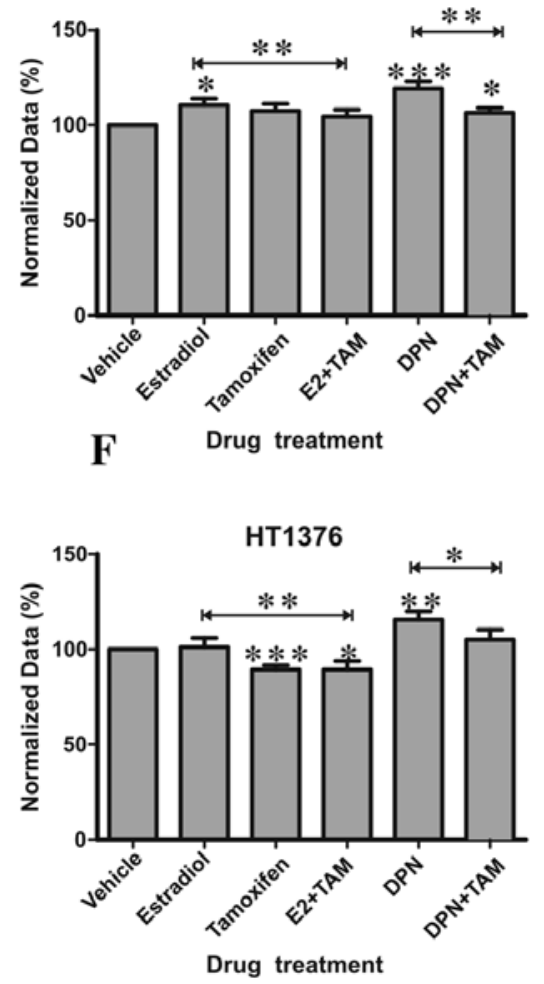

Figure 3. Expression of ER $\alpha$ and ER $\beta$ in human bladder cancer cell lines and effects of estrogenic agonists and antagonists on bladder cancer cell proliferation. mRNA expression of (A) ER $\alpha$ and (B) ER $\beta$ in bladder cancer cell lines normalized to the expression in MCF7 breast cancer cells. Comparison of the effects of $\beta$-estradiol and the ER $\beta$-selective agonist (DPN), in the presence and absence of tamoxifen (TAM) on the proliferation of (C) HTB-1, (D) HTB-3, (E) HTB-5 and (F) HT1376 bladder cancer cells. Statistical significance is indicated relative to control treated cells, except where indicated by bars between treatment groups. ( $\mathrm{P}<0.05,{ }^{* *} \mathrm{P}<0.01,{ }^{* * *} \mathrm{P}<0.001$; ns, not significant). 
outcome, suggesting a model in which estrogen signaling promotes aggressive UCB histology. We additionally found an association between LVI and higher ER $\beta$ levels in the adjacent benign urothelium, raising the possibility of paracrine signaling effects in promoting this aggressive UCB histology. We also investigated for the first time the association between ER $\beta$ expression and clinical risk factors for UCB diagnosis and/or cancer-specific death. We identify a significant association between elevated ER $\beta$ and preoperative hydronephrosis and prior pelvic radiation, both linked to aggressive bladder cancers, suggesting a potential role for ER $\beta$ in these processes. Finally, we noted lower ER $\beta$ levels in patients who had prior intravesical chemotherapy, consistent with a role of $\operatorname{ER} \beta$ in promoting cell cycle progression.

To corroborate our patient findings, we determined the effect of ER $\beta$ activation on the in vitro proliferation of a panel of bladder cancer cell lines. Shen and colleagues (22) previously reported increased proliferation in the RT4 UCB cell line treated with the non-selective ER agonist estradiol; but higher expression of ER $\alpha$ than $E R \beta$ in this cell line raises the possibility that ER $\alpha$ activation was responsible. Another study investigating estradiol in a UCB cell line expressing predominantly ER $\beta$ observed no growth effects (31). Here, we demonstrated that selective $\operatorname{ER} \beta$ activation by DPN in the bladder cancer cells predominantly expressing ER $\beta$ increased proliferation in all cases (Fig. 3C, E and F), whereas DPN had no positive effect on the proliferation of HTB-3 cells with low ER $\beta$ expression (Fig. 3D). These data provide mechanistic evidence that ER $\beta$ activation promotes UCB cell growth, although contrasting with a recent report from Han et al (29) where ER $\beta$ activation reduced UCB migration and invasion.

To explore ER $\beta$ as a therapeutic target, we measured the growth effects of the selective ER modulator (SERM), tamoxifen, in UCB cell lines, with or without simultaneous ER $\beta$ activation using DPN. Several prior studies of SERMs have described conflicting growth inhibitory effects in bladder cancer cell lines or murine xenografts $(21-23,31)$. We found that tamoxifen treatment alone significantly inhibited growth (Fig. 3C and F) of the two cell lines (HTB-1 and HT1376) with high ER $\beta$ expression (Fig. 3B). Tamoxifen also significantly inhibited the proliferative effects of DPN in all 4 bladder cancer cell lines (Fig. 3C-F) when the two treatments were combined, supporting the therapeutic efficacy of selective ER modulators in bladder cancer.

In conclusion, we demonstrated ER $\beta$ upregulation in UCB compared to benign urothelium, consistent with an oncogenic function. Furthermore, we uncovered a stage-independent association between ER $\beta$ levels and: i) aggressive UCB histology and ii) clinical traits carrying a poor prognosis. We provide the first demonstration of ER $\beta$ as an independent predictor of poor cystectomy patient outcomes after adjustment for tumor stage, lymph node involvement and LVI. We demonstrated that ER $\beta$ activation increases UCB cell proliferation but can be effectively blocked by SERM pharmacotherapy. Although the relationship between ER $\beta$ and tumor stage and patient outcomes is disputed $(22,25,26)$, our research supports a role for ER $\beta$ in promoting aggressive bladder cancer and suggests that pharmacological targeting of estrogen signaling pathways may be useful in treating this disease.

\section{Acknowledgements}

The authors gratefully acknowledge the institutional financial support of Weill Cornell Medical College, the University of Nottingham and an F31 Fellowship from NIH (NIDCR) (K.M.).

\section{References}

1. Siegel R, Naishadham D and Jemal A: Cancer statistics, 2012. CA Cancer J Clin 62: 10-29, 2012.

2. Stein JP, Lieskovsky G, Cote R, et al: Radical cystectomy in the treatment of invasive bladder cancer: long-term results in 1,054 patients. J Clin Oncol 19: 666-675, 2001.

3. Messing E: Urothelial tumors of the bladder. In: CampbellWalsh Urology. Wein AJ (ed). 9th edition. Saunders Elsevier, Philadelphia, pp2407-2446, 2007.

4. Shariat SF, Karakiewicz PI, Palapattu GS, et al: Outcomes of radical cystectomy for transitional cell carcinoma of the bladder: a contemporary series from the Bladder Cancer Research Consortium. J Urol 176: 2414-2422, 2006.

5. Madeb R and Messing EM: Gender, racial and age differences in bladder cancer incidence and mortality. Urol Oncol 22: 86-92, 2004.

6. Tilki D, Svatek RS, Karakiewicz PI, et al: Characteristics and outcomes of patients with pT4 urothelial carcinoma at radical cystectomy: a retrospective international study of 583 patients. J Urol 183: 87-93, 2010

7. May M, Bastian PJ, Brookman-May S, et al: Gender-specific differences in cancer-specific survival after radical cystectomy for patients with urothelial carcinoma of the urinary bladder in pathologic tumor stage T4a. Urol Oncol, Nov 4, 2011 (Epub ahead of print).

8. Palou J, Sylvester RJ, Faba OR, et al: Female gender and carcinoma in situ in the prostatic urethra are prognostic factors for recurrence, progression, and disease-specific mortality in T1G3 bladder cancer patients treated with bacillus CalmetteGuérin. Eur Urol 62: 118-125, 2012.

9. Scosyrev E, Noyes K, Feng C and Messing E: Sex and racial differences in bladder cancer presentation and mortality in the US. Cancer 115: 68-74, 2009.

10. Shariat SF, Chromecki TF, Cha EK, et al: Risk stratification of organ-confined bladder cancer after radical cystectomy using cell cycle-related biomarkers. J Urol 187: 457-462, 2012.

11. Tilki D, Reich O, Svatek RS, et al: Characteristics and outcomes of patients with clinical carcinoma in situ only treated with radical cystectomy: an international study of 243 patients. J Urol 183: 1757-1763, 2010.

12. Tilki D, Svatek RS, Novara G, et al: Stage pT0 at radical cystectomy confers improved survival: an international study of 4,430 patients. J Urol 184: 888-894, 2010.

13. van Rhijn BW, van der Kwast TH, Alkhateeb SS, et al: A new and highly prognostic system to discern $\mathrm{T} 1$ bladder cancer substage. Eur Urol 61: 378-384, 2012.

14. Imamov O, Yakimchuk K, Morani A, et al: Estrogen receptor beta-deficient female mice develop a bladder phenotype resembling human interstitial cystitis. Proc Natl Acad Sci USA 104: 9806-9809, 2007

15. May M, Stief C, Brookman-May S, et al: Gender-dependent cancer-specific survival following radical cystectomy. World J Urol 30: 707-713, 2011.

16. Davis-Dao CA, Henderson KD, Sullivan-Halley J, et al: Lower risk in parous women suggests that hormonal factors are important in bladder cancer etiology. Cancer Epidemiol Biomarkers Prev 20: 1156-1170, 2011.

17. McGrath M, Michaud DS and De Vivo I: Hormonal and reproductive factors and the risk of bladder cancer in women. Am J Epidemiol 163: 236-244, 2006.

18. Prizment AE, Anderson KE, Harlow BL and Folsom AR: Reproductive risk factors for incident bladder cancer: Iowa Women's Health Study. Int J Cancer 120: 1093-1098, 2007.

19. Thomas $C$ and Gustafsson JA: The different roles of ER subtypes in cancer biology and therapy. Nat Rev Cancer 11: 597-608, 2011.

20. Kim HT, Kim BC, Kim IY, et al: Raloxifene, a mixed estrogen agonist/antagonist, induces apoptosis through cleavage of BAD in TSU-PR1 human cancer cells. J Biol Chem 277: 32510-32515, 2002. 
21. $\mathrm{Pu}$ YS, Hsieh TS, Cheng AL, et al: Combined cytotoxic effects of tamoxifen and chemotherapeutic agents on bladder cancer cells: a potential use in intravesical chemotherapy. Br J Urol 77: 76-85, 1996.

22. Shen SS, Smith CL, Hsieh JT, et al: Expression of estrogen receptors- $\alpha$ and $-\beta$ in bladder cancer cell lines and human bladder tumor tissue. Cancer 106: 2610-2616, 2006.

23. Sonpavde G, Okuno N, Weiss H, et al: Efficacy of selective estrogen receptor modulators in nude mice bearing human transitional cell carcinoma. Urology 69: 1221-1226, 2007.

24. Kontos S, Papatsoris A, Kominea A, et al: Expression of ER $\beta$ and its co-regulators $\mathrm{p} 300$ and $\mathrm{NCoR}$ in human transitional cell bladder cancer. Urol Int 87: 151-158, 2011.

25. Kontos S, Kominea A, Melachrinou M, Balampani E and Sotiropoulou-Bonikou G: Inverse expression of estrogen receptor- $\beta$ and nuclear factor- $\kappa \mathrm{B}$ in urinary bladder carcinogenesis. Int J Urol 17: 801-809, 2010.

26. Tuygun C, Kankaya D, Imamoglu A, et al: Sex-specific hormone receptors in urothelial carcinomas of the human urinary bladder: a comparative analysis of clinicopathological features and survival outcomes according to receptor expression. Urol Oncol 29: 43-51, 2011.
27. Kauffman EC, Robinson BD, Downes MJ, et al: Role of androgen receptor and associated lysine-demethylase coregulators, LSD1 and JMJD2A, in localized and advanced human bladder cancer. Mol Carcinog 50: 931-944, 2011.

28. Teng J, Wang ZY, Jarrard DF and Bjorling DE: Roles of estrogen receptor $\alpha$ and $\beta$ in modulating urothelial cell proliferation. Endocr Relat Cancer 15: 351-364, 2008.

29. Han B, Cui D, Jing Y, Hong Y and Xia S: Estrogen receptor $\beta$ $(\mathrm{ER} \beta)$ is a novel prognostic marker of recurrence survival in non-muscle-invasive bladder cancer potentially by inhibiting cadherin switch. World J Urol 30: 861-867, 2012.

30. Miyamoto H, Yao JL, Chaux A, et al: Expression of androgen and oestrogen receptors and its prognostic significance in urothelial neoplasm of the urinary bladder. BJU Int 109: 1716-1726, 2012.

31. Waliszewski P, Waliszewska MK, Hemstreet GP III and Hurst RE: Expression of sex steroid receptor genes and comodulation with retinoid signaling in normal human uroepithelial cells and bladder cancer cell lines. Urol Oncol 3: 141-147, 1997. 